\title{
Expression and prognostic value of cell- cycle-associated genes in gastric adenocarcinoma
}

\author{
Dongya Wang ${ }^{1 \dagger}$, Haige Zhu ${ }^{2 \dagger}$, Meng Guo ${ }^{3,4^{*}}$ (D) Xiaotong Fan ${ }^{3,4}$, Shuangshuang Hu ${ }^{5}$, Kemin Yan ${ }^{5}$, Jia Sun ${ }^{5}$, \\ Jiaojiao Wang ${ }^{5}$, Miaomiao Li ${ }^{5}$, Haijuan Xiao ${ }^{4,5}$ and Zhiguo Liu, Li, $^{3 *}$
}

\begin{abstract}
Background: Gastric carcinoma is a malignant disease, and gastric adenocarcinoma (GAC) is the most common histological type. Molecular profiling of GAC has been extensively performed, but few have focused on the clinical significance of gene clusters of the cell cycle.

Methods: We investigated the genetic profile of cell-cycle-associated genes in a GAC cohort. The mRNA expression and clinical data were downloaded from TCGA, according to cBioportal. We conducted a series of analyses to detect the relationships between these genes and GAC.

Results: From all the patients, 5 clusters were identified based on mRNA expression of 122 cell-cycle-associated genes. Cluster 1 showed the worst prognosis and is characterized by extremely high expression of WEE2 and CCNE1. Comparison of the gene patterns showed that 16 genes expressed were distinctly varied between each cluster. In addition, investigations into the prognostic role of the 16 genes suggested that high expression of ESPL1 and MCM5 were significantly correlated with favorable outcomes. Moreover, we detected that ESPL1 and MCM5 gene expression were negatively correlated with GAC pathologic stage progression.

Conclusions: This study revealed a gene expression pattern of the cell cycle in different GAC subgroups, and suggested individual genes were associated with the clinical outcome and AJCC stages. These results suggest a novel prognostic strategy for GAC and provide information for patient stratification and trials of targeted therapies.
\end{abstract}

Keywords: Gastric adenocarcinoma, Cell cycle, Gene expression, Tumor stages, Prognostic implications

\section{Background}

Gastric carcinoma (GC) remains the fifth most prevalent cancer and the third leading cause of cancer-related deaths worldwide [1, 2]. Gastric adenocarcinoma (GAC) is the main type of $\mathrm{GC}$ and is associated with poor survival rates [1]. Although the incidence of GAC has been reduced over the past years, it imposes a critical issue globally [3]. The characteristics of diverse histological (phenotypes) and genotypes manifest that GAC is a heterogeneous disease [4]. Previous studies uncovered the genetic profiling of GAC by performing gene expression or DNA sequencing, but rare

\footnotetext{
* Correspondence: guomengfudan@yeah.net; liuzhiguo@fmmu.edu.cn ${ }^{\dagger}$ Dongya Wang and Haige Zhu contributed equally to this work.

${ }^{3}$ Xijing Hospital of Digestive Diseases, Fourth Military Medical University, Xi'an 710000, Shaanxi, China

Full list of author information is available at the end of the article
}

profiling led to alterations of gene panels associated with specific biological events [5-7]. The cell cycle process is a highly organized event and regulated duplication of genetic material and cell division, and aberrant cell cycle activity is a hallmark of cancer [8]. A comprehensive molecular characterization study elicited frequent amplifications of cell cycle mediators (CCNE1, CCND1 and CDK6) in GAC; however, it remains unclear if specific patterns of cell-cycle-associated gene expression across different subtypes or stages bears any significance on patient outcome or is correlated with genetic alterations [9].

Tumor stages are generally used to characterize disease progression and determine metastasis and prognosis [10]. Gene expression involved in the development of GC is also variant in different stages [11]. In this study, we focused on mRNA expressing variations of genes

(c) The Author(s). 2018 Open Access This article is distributed under the terms of the Creative Commons Attribution 4.0 International License (http://creativecommons.org/licenses/by/4.0/), which permits unrestricted use, distribution, and 
associated with the cell cycle in different GAC subgroups, as well as its correlation to tumor stages. We identified significantly differentially expressed genes in GAC samples and the prognostic impact [12]. Specific genes that impacted the outcomes showed a variant expression panel between different stages. Finally, we report a unique set of cell-cycle-associated genes in GAC that serve as a divider of biological characteristics, which revealed the potential for therapeutic strategy targeting cell-cycle-associated genes.

\section{Methods}

\section{Samples and database}

We obtained RNA-Seq data and the corresponding clinical records of 415 gastric adenocarcinoma patients (GAC) of TCGA from cBioPortal for Cancer Genomics (http://cbioportal.org) [13]. We filtrated the data base on whether the mRNA z-score, tumor stage and overall survival were clearly recorded. Collectively, the data set included 228 samples for the clustering study and 206 samples for the stage study, respectively.

A panel of cell-cycle-associated genes was derived from the KEGG pathway database (http://www.kegg.jp/ kegg/), as previously described [14]. In total, 124 genes were listed; however, mRNA expression data of genes $M Y C$ and $C C N D 1$ were unobtainable, and the remaining 122 candidate genes were analyzed (Additional file 1: Table S1).

\section{Bioinformatics}

Hierarchical cluster analysis of 122 genes expressed in each sample was used to group samples with similar gene expression patterns. Samples with differential cell-cycle-associated gene expression between separate clusters were identified from the whole data set. The expression levels of GAC patients were shown as mRNA z-scores and grouped using the hierarchical clustering algorithm in the Gene Cluster 3.0 program [15]. The heat-map of cluster indication and tumor stage divided pattern was generated using the Java Treeview program [16].

\section{Prognostic implication analyses}

To evaluate the relationship between the cell-cycle-associated genes and patient clinical outcome, we used GraphPad Prism 6 for Windows (GraphPad Software, Inc., California, US; Version 6.01, 2012) for construction and overall survival (OS) comparisons in different gastric adenocarcinoma clusters and different tumor stages. Additionally, OS difference analysis between low and high expression cohorts were conducted in GraphPad Prism 6.

\section{Statistical analysis}

Survival curves were plotted using a Kapla-Meier analysis and compared using the log-rank test in GraphPad Prism 6. Associations between clinical characteristics and clustering variable were analyzed by Fisher's exact test and Pearson/Spearman correlation. Difference of gene expression between clusters was conducted by ANOVA analysis. Correlation between each element was conducted by regression analysis. Both results were performed in SPSS 19.0 (IBM, Inc., New York, US). A $P$ value of less than 0.05 was considered statistically significant.

\section{Results}

Expression profile of cell-cycle-associated genes in GAC

To understand biological functions and utilities of the biological system, we retrieved 124 cell-cycle-associated genes (PATHWAY: map04110) from the KEGG database. Additionally, we selected 122 genes that were detectable and sorted the mRNA expression values from the RNA-seq data of GAC (Additional file 2: Figure S1).

The expression levels of the 122 genes were calculated by mRNA z-scores compared to the expression distribution of each gene from tumors that were diploid for the genes in 415 GAC cases (RNA Seq V2 RSEM), based on TCGA data in GC. Following the clinical filtrated criteria, we achieved 228 cases with survival records to perform cluster analysis. Five clusters of GAC were distinguished based on the gene expression panels (Fig. 1a). The statistical analysis of the clinical and histological characteristics of each clusters was performed, and the result shows that the nodes pathologic stages and tumor stages was significantly different (The characteristic of histological types was excluded for the reason of the incompleteness of data) (Table 1). Moreover, correlational analysis showed the significant correlations of the three parameters and clustering situation (Table 1).

We compared the median survival and survival curves between each cluster further and the results showed that cluster 1 demonstrated the worst prognosis (12.35 months) compared to other clusters (26.31 months) (Fig. 1b). In contrast, clusters 2 and 4 showed favorable prognosis with a median survival of 30.88 months and 26.45 months, respectively (Table 2). Comparison of survival curves revealed a significant difference between outcomes of cluster 1 and cluster $4(P=0.0278)$ (Additional file 1: Table S2).

\section{Variation of cell-cycle-associated gene expression in different clusters}

Additionally, we examined the genes that expressed variation between each cluster. According to the filter criteria of significant difference $(P<0.01)$, there were 42 differentially expressed genes of cluster 1 versus the other clusters, 32 differentially expressed genes of cluster 1 versus cluster 


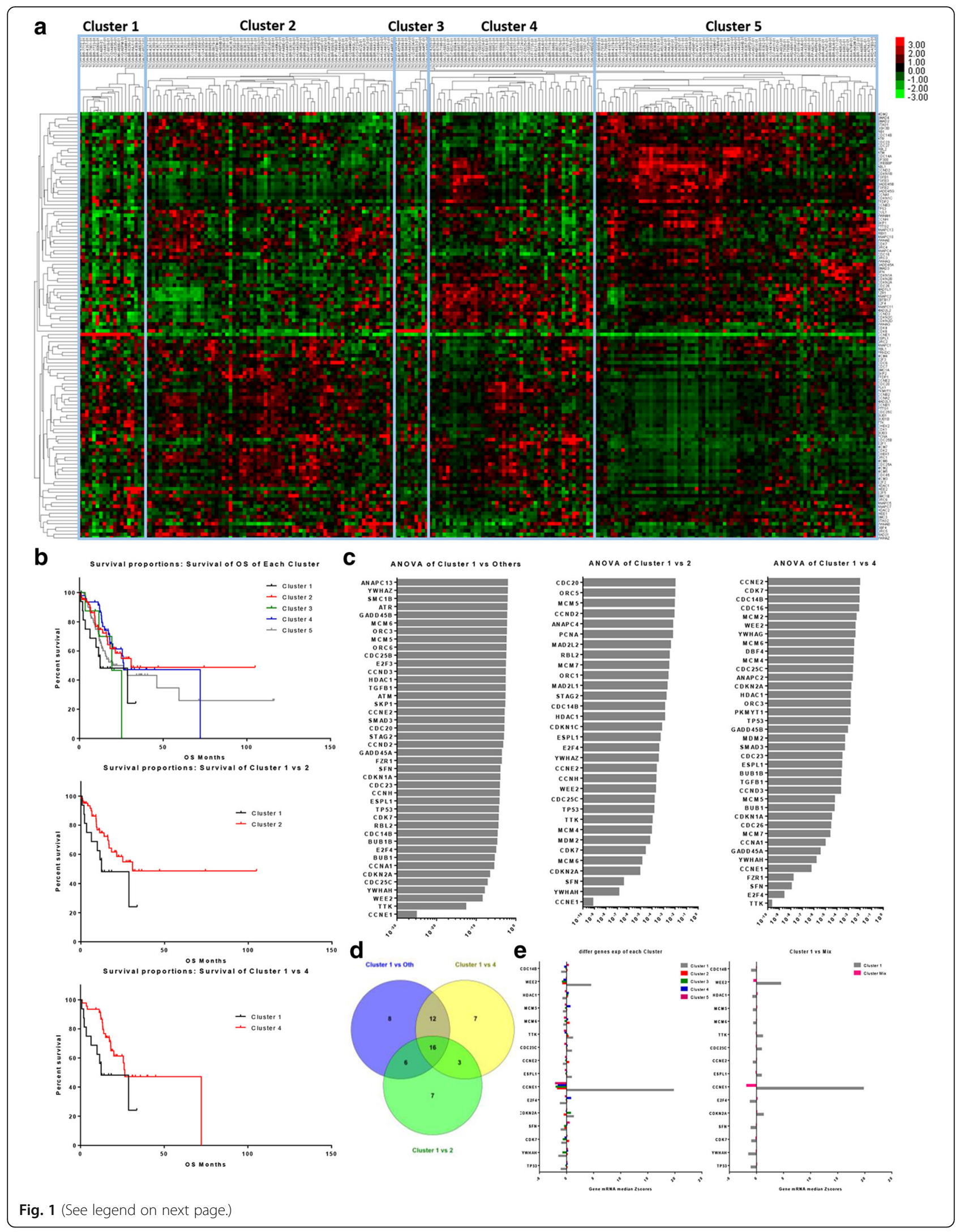


(See figure on previous page.)

Fig. 1 Differential expression of cell-cycle-associated genes in each cluster. a, The GAC patients were divided into 5 clusters based on mRNA expression levels. b, Survival difference between all clusters (top chart), cluster 1 versus cluster 2 (middle chart) and cluster 1 versus cluster 4 . c, Differentiation of gene expression between clusters were detected: cluster 1 and other clusters (left); cluster 1 and cluster 2 (middle); cluster 1 and cluster 4 (right). d, There are 16 genes presented in the overlap of differentiation sets. e, WEE2 and CCNE1 showed the most distinct changes in comparison, no matter of cluster 1 and other clusters, nor of cluster 1 and other total patients

Table 1 The clinical and histological characteristics of each clusters

\begin{tabular}{|c|c|c|c|c|c|c|c|c|}
\hline \multicolumn{2}{|l|}{ Cluster } & $\begin{array}{l}1 \\
(n=15)\end{array}$ & $\begin{array}{l}2 \\
(n=10)\end{array}$ & $\begin{array}{l}3 \\
(n=47)\end{array}$ & $\begin{array}{l}4 \\
(n=63)\end{array}$ & $\begin{array}{l}5 \\
(n=71)\end{array}$ & $P$-value & $\begin{array}{l}\text { Correlation } \\
\text { coefficient }\end{array}$ \\
\hline & & & & & & & & \\
\hline Age (mean) & & 62.7 & 64.1 & $6 / .2$ & 65.2 & 63.6 & 0.406 & -0.061 \\
\hline \multirow[t]{2}{*}{ Gender } & Male & 12 & 7 & 25 & 42 & 40 & 0.255 & $0.178^{c}$ \\
\hline & Female & 3 & 3 & 22 & 21 & 31 & & \\
\hline \multirow[t]{4}{*}{ Race } & Asian & 5 & 3 & 12 & 9 & 15 & 0.309 & 0.093 \\
\hline & White & 10 & 7 & 30 & 47 & 49 & & \\
\hline & Black & 0 & 0 & 3 & 1 & 0 & & \\
\hline & $N A^{a}$ & 0 & 0 & 2 & 6 & 7 & & \\
\hline \multirow[t]{4}{*}{ Grade } & G1 & 0 & 0 & 0 & 0 & 3 & 0.104 & $0.178^{c}$ \\
\hline & G2 & 6 & 2 & 14 & 12 & 6 & & \\
\hline & G3 & 9 & 8 & 32 & 50 & 60 & & \\
\hline & GX & 0 & 0 & 1 & 1 & 2 & & \\
\hline \multirow[t]{3}{*}{ Histological diagnosis (GAC) } & Signet ring type & 1 & 0 & 2 & 2 & 6 & / & / \\
\hline & Diffuse type & 2 & 2 & 10 & 18 & 34 & & \\
\hline & NOS $^{b}$ & 12 & 8 & 35 & 43 & 31 & & \\
\hline \multirow[t]{2}{*}{ History of other malignancy } & Yes & 1 & 0 & 1 & 1 & 4 & 0.595 & -.057 \\
\hline & No & 14 & 10 & 46 & 62 & 67 & & \\
\hline \multirow[t]{2}{*}{ Neoadjuvant therapy } & Yes & 0 & 0 & 0 & 0 & 0 & / & / \\
\hline & No & 15 & 10 & 47 & 63 & 71 & & \\
\hline \multirow[t]{4}{*}{ Tumor pathologic (AJCC PT) } & $\mathrm{T} 1$ & 1 & 0 & 1 & 3 & 1 & 0.136 & .089 \\
\hline & $\mathrm{T} 2$ & 3 & 1 & 13 & 16 & 11 & & \\
\hline & $\mathrm{T} 3$ & 8 & 5 & 15 & 34 & 30 & & \\
\hline & $\mathrm{T} 4$ & 3 & 4 & 18 & 10 & 29 & & \\
\hline \multirow[t]{5}{*}{ Nodes pathologic (AJCC PN) } & NO & 6 & 3 & 25 & 24 & 17 & 0.009 & $0.165^{c}$ \\
\hline & N1 & 4 & 4 & 7 & 17 & 20 & & \\
\hline & N2 & 1 & 2 & 8 & 7 & 15 & & \\
\hline & N3 & 3 & 0 & 7 & 15 & 19 & & \\
\hline & NX & 1 & 1 & 0 & 0 & 0 & & \\
\hline \multirow[t]{3}{*}{ Metastasis pathologic (AJCC PM) } & MO & 14 & 10 & 43 & 56 & 61 & 0.211 & 0.093 \\
\hline & M1 & 0 & 0 & 0 & 6 & 7 & & \\
\hline & MX & 1 & 0 & 4 & 1 & 3 & & \\
\hline \multirow[t]{4}{*}{ Tumor stage } & Stage I & 1 & 0 & 10 & 11 & 5 & 0.006 & $0.252^{d}$ \\
\hline & Stage II & 9 & 8 & 20 & 25 & 20 & & \\
\hline & Stage III & 4 & 2 & 17 & 20 & 38 & & \\
\hline & Stage IV & 1 & 0 & 0 & 7 & 8 & & \\
\hline
\end{tabular}

${ }^{\mathrm{a}} \mathrm{NA}$ represents not available

${ }^{\mathrm{b}} \mathrm{NOS}$ represents not otherwise specified

'The correlation was significant when the confidence coefficient (double measurement) was 0.05

${ }^{d}$ The correlation was significant when the confidence coefficient (double measurement) was 0.01 
Table 2 Median survival of each cluster

\begin{tabular}{llllll}
\hline & Cluster 1 & Cluster 2 & Cluster 3 & Cluster 4 & Cluster 5 \\
\hline Number of rows & 19 & 71 & 10 & 47 & 81 \\
$\begin{array}{l}\text { Median survival } \\
\text { (Months) }\end{array}$ & 12.35 & 30.88 & 19.32 & 26.45 & 19.94 \\
\hline
\end{tabular}

2 and 38 differentially expressed genes of cluster 1 versus cluster 4 (Fig. 1c). A cross-reference of the three gene groups showed that 16 genes were included in the overlaps (Fig. 1d). A comparison of the 16 genes of mRNA expression demonstrated that WEE2 and CCNE1 were dramatically elevated in cluster $1(P=2.89085 \mathrm{E}-09$ and $P=6.96046 \mathrm{E}-26$, respectively) (Fig. $1 \mathrm{e}$ and Additional file 1: Table S3).

\section{Expression of cell-cycle-associated genes were correlated with prognosis in GAC}

To address the prognostic roles of genes with cluster-differential expression, we evenly divided the samples into two groups based on the mRNA z-scores from high values to low values. Survival curves according to each single gene are shown in Fig. 2. Comparison of the median survival and survival curves in the 16 genes between low-expression and high-expression groups revealed that ESPL1 and MCM5 were significantly associated with clinical outcome $(P=0.0448$ and 0.0048 , respectively) (Table 3 ). High expression of ESPL1 and MCM5 indicated a favorable median survival (18.33 vs 28.71 months and 19.94 vs 59.49 months, respectively). In addition, elevated CCNE2 and TTK expression also showed a trend of correlation with good prognosis, but with a non-significant difference (Table 3).

\section{Expression of ESPL1 and MCM5 were associated with tumor stage progression}

To detect the impacted factors of differential gene expression, we filtered out a sample set with intact pathologic records. According to investigating the expression of cluster 1-specific genes corresponding to each clinical manifestation, we detected obvious differences of the 16 genes expressed in each tumor stage (Fig. 3a). In

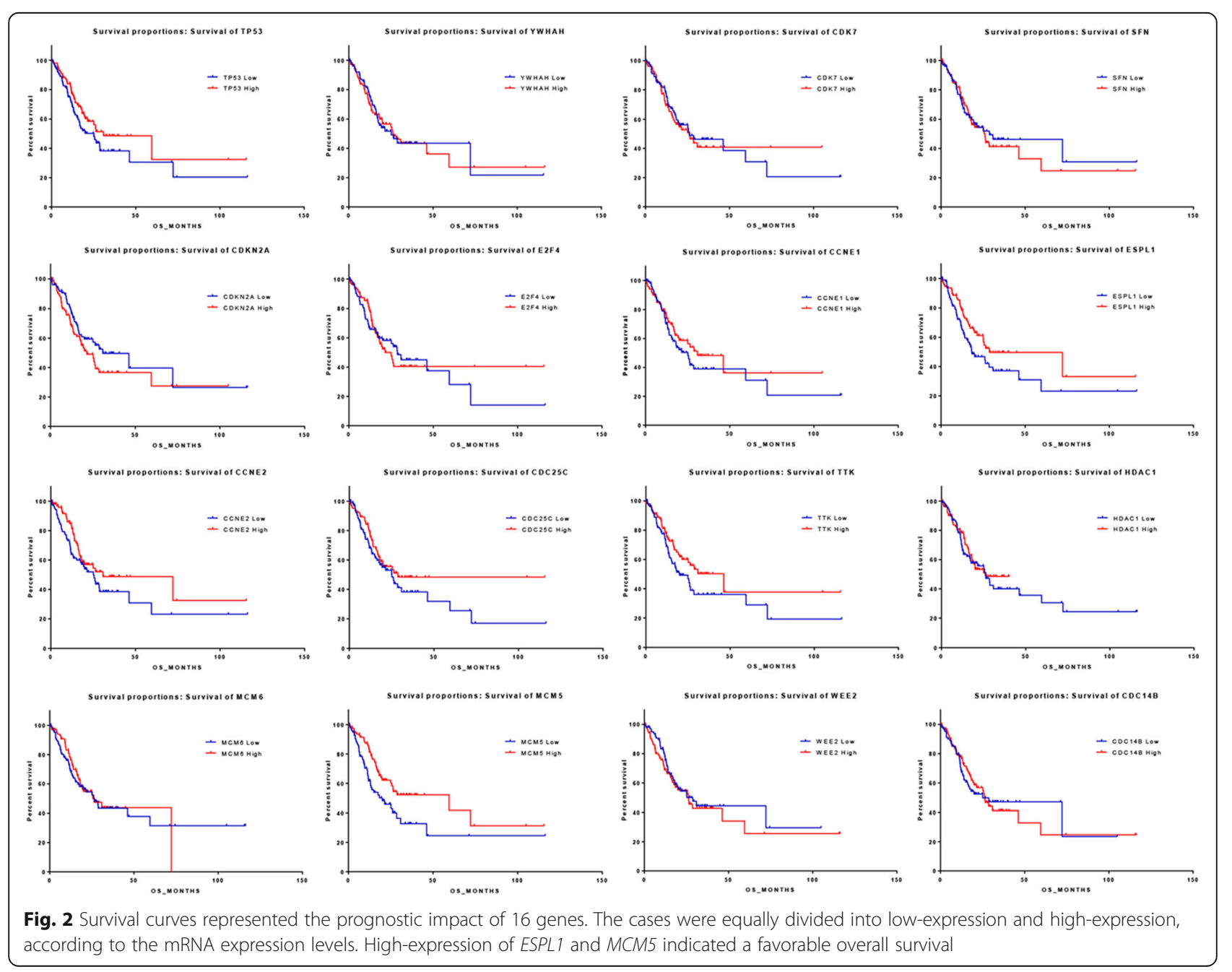


Table 3 Comparison of survival curves of low and high expression groups of each cluster differ-expressed gene by Log-rank (Mantel-Cox) test

\begin{tabular}{|c|c|c|c|c|c|c|}
\hline $\begin{array}{l}\text { Cluster differ-expressed } \\
\text { genes }\end{array}$ & Chi square & $d f$ & $P$ value & $\begin{array}{l}\text { Significant } \\
\text { different }^{\mathrm{a}}\end{array}$ & $\begin{array}{l}\text { Median survival } \\
\text { of Low-Exp. (Months) }\end{array}$ & $\begin{array}{l}\text { Median survival } \\
\text { of High-Exp. (Months) }\end{array}$ \\
\hline TP53 & 2.283 & 1 & 0.1308 & ns & 25.16 & 30.88 \\
\hline YWHAH & 0.02811 & 1 & 0.8669 & ns & 25.16 & 26.31 \\
\hline CDK7 & 0.1239 & 1 & 0.7248 & ns & 26.08 & 26.31 \\
\hline SFN & 0.06809 & 1 & 0.7941 & ns & 28.71 & 26.08 \\
\hline CDKN2A & 2.168 & 1 & 0.141 & ns & 30.88 & 21.42 \\
\hline E2F4 & 0.04874 & 1 & 0.8253 & ns & 28.71 & 25.03 \\
\hline CCNE1 & 1.126 & 1 & 0.2887 & ns & 25.16 & 30.88 \\
\hline ESPL1 & 4.025 & 1 & 0.0448 & * & 18.33 & 28.71 \\
\hline CCNE2 & 3.125 & 1 & 0.0771 & ns & 25.16 & 30.88 \\
\hline CDC25C & 1.725 & 1 & 0.189 & ns & 25.16 & 28.71 \\
\hline TTK & 3.175 & 1 & 0.0748 & ns & 19.88 & 46.22 \\
\hline MCM6 & 0.2145 & 1 & 0.6433 & ns & 26.45 & 25.59 \\
\hline MCM5 & 7.939 & 1 & 0.0048 & $* *$ & 19.94 & 59.49 \\
\hline $\mathrm{HDACl}$ & 0.3977 & 1 & 0.5283 & ns & 26.08 & 26.45 \\
\hline WEE2 & 0.6097 & 1 & 0.4349 & ns & 28.71 & 26.31 \\
\hline$C D C 14 B$ & 0.1163 & 1 & 0.7331 & ns & 25.03 & 26.31 \\
\hline
\end{tabular}

${ }^{a} \mathrm{~ns}$ represents non-significance

${ }^{*} P$ values were less than 0.05 and equal or greater than 0.01

**P values were less than 0.01

addition, ESPL1 and MCM5 expression were negatively correlated with tumor stage progression (Fig. 3b, c), and regression analysis indicated that ESPL1 and MCM5 were correlated to tumor stages (Pearson correlation $=-$ $0.25713 ; \quad P=9.54 \mathrm{E}-05$ and Pearson correlation $=-$ $0.13982 ; P=0.023$, respectively) (Additional file 1: Table S4).

Additionally, we investigated the correlation between cluster 1 specifically expressed genes and tumor stages. There were 15 genes, including ESPL1 and MCM5, that showed relativity $(P<0.05)$ with tumor stage changing (Fig. 3b) (Additional file 1: Table S4). A correlation matrix of each gene and stage showed that FZR1 was also weakly correlated with stages (Pearson correlation $=-0.20806 ; P$ $=0.001)$. What's more, we detected that the expression of ESPL1 was positively correlated with the expression of FZR1, SFN, MCM5, CDC20 and CDC25C and negatively correlated with the expression of GADD45B and ANAPC13. MCM5 was positively correlated with the expression of CDC25C, ESPL1, FZR1 and CDC20 and negatively correlated with the expression of $S M A D 2, R B L 2$, GADD45B and ANAPC13 (Table 4) (Fig. 3c, d).

In summary, we studied the expression profiles of 122 cell-cycle-associated genes and sorted the GAC samples into 5 clusters according to mRNA z-score distribution. Sixteen specific genes showed differential expression between each cluster that were identified. We examined the prognostic roles of the 16 genes and detected that
ESPL1 and MCM5 were significantly associated with overall survival. Moreover, we detected that the expression of ESPL1 and MCM5 were negatively correlated with tumor stage progression. These results suggested the significance of cell-cycle-related gene expression in the development and progression of GAC and provided potential targets for GAC therapy.

\section{Discussion}

Uncontrolled tumor cell proliferation via aberrant expression of various cell cycle genes is one of the most essential features in multiple cancers. Therefore, cell-cycle-regulated genes are considerable targets in cancer therapy [17]. Through this study of the mRNA expression of 122 cell-cycle-associated genes, we demonstrated a molecular profile, which defined five genomic clusters of GAC. Among them, cluster 1 manifested the worst survival and was characterized by dramatically elevated expression of WEE2 and CCNE1. WEE2 is an oocyte-specific protein tyrosine kinase that phosphorylates and inhibits CDK1, and acts as a key regulator of meiosis during both prophase I and metaphase II [18]. In GAC, WEE2 might play a similar role by mediated the CDK1 phosphorylation. Amplification of CCNE1 (G1/S-specific cyclin-E1) is associated with poor outcome in breast, lung, and other solid cancers [19]. However, prognosis implication analysis of single genes did not show any correlation of unfavorable outcome and 


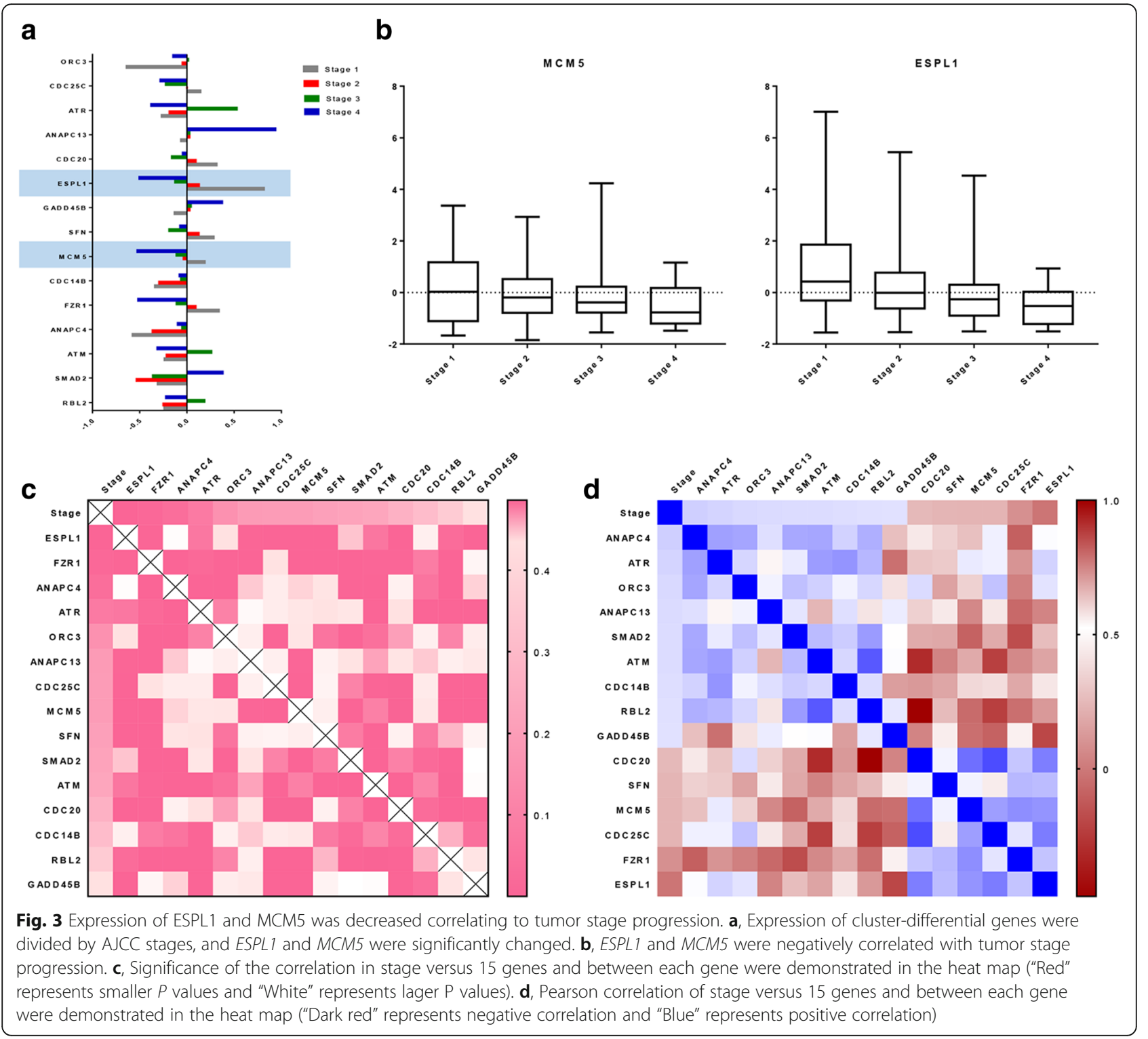

Table 4 Correlation between MCM5/ESPL1 and tumor stages-mutative genes

\begin{tabular}{|c|c|c|c|c|c|c|}
\hline \multirow[t]{2}{*}{ Correlation } & \multicolumn{3}{|l|}{ MCM5 } & \multicolumn{3}{|l|}{ ESPL1 } \\
\hline & Genes & Person correlation $^{\dagger}$ & Significance ${ }^{\ddagger}$ & Genes & Person correlation $^{\dagger}$ & Significance $^{\ddagger}$ \\
\hline \multirow[t]{5}{*}{ Positive } & CDC25C & 0.379754 & 9.02914E-09 & $F Z R 1$ & 0.231261 & 0.000412193 \\
\hline & ESPL1 & 0.419389 & $1.75479 \mathrm{E}-10$ & SFN & 0.259065 & $8.49402 \mathrm{E}-05$ \\
\hline & FZR1 & 0.442699 & $1.34359 E-11$ & MCM5 & 0.419389 & 1.75479E-10 \\
\hline & $C D C 20$ & 0.561659 & 7.9853E-19 & $C D C 20$ & 0.502711 & $6.81739 \mathrm{E}-15$ \\
\hline & & & & CDC25C & 0.51131 & $2.0258 \mathrm{E}-15$ \\
\hline \multirow[t]{4}{*}{ Negative } & SMAD2 & -0.29366 & $9.18019 \mathrm{E}-06$ & GADD45B & -0.34282 & $2.27821 \mathrm{E}-07$ \\
\hline & $R B L 2$ & -0.27645 & 2.88184E-05 & ANAPC13 & -0.22992 & 0.000442825 \\
\hline & GADD45B & -0.26908 & 4.59871E-05 & & & \\
\hline & ANAPC13 & -0.2219 & 0.000673931 & & & \\
\hline
\end{tabular}


highly expressed WEE2 and CCNE1 $(P=0.4349$ and $P=$ 0.2887 , respectively). This discrepancy revealed that WEE2 and CCNE1 were indirectly regulated the GAC by triggering other molecular events.

In entire GAC cases, we detected that elevated ESPL1 and MCM5 expression were significantly associated favorable prognosis, and the expression variability were reversely consisted with stage progression. ESPL1, a protease (Separase) encoded gene, was reported overexpressing in mammary adenocarcinomas and related to tumor initiation and progression, but not mentioned in GAC [20]. According to cleavage of cohesin complex subunit, ESPL1 might promote metaphase/anaphase transition during the cell cycle in GAC [21]. MCM5, minichromosome maintenance complex component 5, which encoded protein is involved in the initiation of DNA replication and the effect might reduce the accumulation of genetic variation in GAC. The prognostic analysis of MCM5 in current study showed that the upregulated MCM5 was associated with a favorable prognosis. This result was in accordance with an previous immunohistochemical study, which suggested that patients with high MCM5 expression had significantly shorter survival times and MCM5 was associated with clinicopathological parameters in gastric adenocarcinoma [22]. Besides, additional 13 genes specifically expressed in cluster 1 were also correlated to tumor stage. The regression analysis showed that ESPL1 and MCM5 was positively correlated (Person $=0.419389, P=1.75479 \mathrm{E}-10)$ and both them were correlated to other cell cycle-specific genes expression, suggesting a co-regulation effect through genes expression changing in GAC.

Although previous studies revealed the significant role of cell cycle associated genes in gastric cancer, most works were focus on individual genes [23-25]. In current study, we discuss the panorama of cell cycle associated genes in GAC samples. Those results might appeal to the further studies of various cell cycle inhibitors with therapeutic potential. For example, evaluation of cell cycle derangement in thyroid tumors may serve as a useful tool for both DTC diagnosis and prognosis [26]; PLK1 and AK inhibitors display the potential for being employed in innovative therapeutic strategies for improving T-ALL patient outcome [27]; Inhibition of Aurora and Polo-like kinases suggest that targeting G2-M regulators may represent a novel approach for treatment of human [28].

\section{Conclusions}

Irrespective of tissue origin and adjuvant therapy, this work revealed the gene expression profile of cell cycle association in GAC. The impact and functions of distinctive genes need to be further investigated. We believe these results will facilitate the exploration of novel therapies, ultimately improving clinical outcome from this intractable disease.

\section{Additional files}

\begin{abstract}
Additional file 1: Table S1. Gene listed in KEGG cell cycle pathway (hsa04110). Table S2. Comparison of Survival Curves of each cluster by Log-rank (Mantel-Cox) test. Table S3. Comparison of individual gene expressions of each cluster. Table S4. Correlation between Cluster-specific genes expression and tumor stages. (DOCX 24 kb).
\end{abstract}

Additional file 2: Figure S1. Networks of cell cycle associated genes. The interaction values between each connected gene were exported from String-db. (TIF $1159 \mathrm{~kb}$ ).

\section{Abbreviations}

AJCC: American Joint Committee on Cancer; DTC: Differentiated thyroid carcinoma; GAC: Gastric adenocarcinoma; GC: Gastric carcinoma; KEGG: Kyoto encyclopedia of genes and genomes; RNA: Ribonucleic acid; RNA-seq: Whole transcriptome sequencing; T-ALL: T-cell acute lymphoblastic leukemia;

TCGA: The cancer genome atlas

\section{Funding}

This work was funded by the National Natural Science Foundation of China (Nos. 81702355, 81372387, 81572820).

Availability of data and materials

The datasets analysed during the current study are available in the TCGA repository (http://www.cbioportal.org/).

\section{Authors' contributions}

DW designed the current study. $\mathrm{HZ}$ analyzed and interpreted the data. XF, SH and KY collected the data. JS, JW and ML performed the examination and the sorting of the clinical information. HX performed the statistical test. $M G$ and $Z L$ writing the manuscript. All authors read and approved the final manuscript.

\section{Ethics approval and consent to participate}

Data obtained from the TCGA open-access database was collected from tumors of patients who provided informed consent based on the guidelines from the TCGA Ethics, Law and Policy Group.

\section{Competing interests}

The authors declare that they no competing interests.

\section{Publisher's Note}

Springer Nature remains neutral with regard to jurisdictional claims in published maps and institutional affiliations.

\section{Author details \\ ${ }^{1}$ General Surgery Department, The Affiliated Hospital of Jinggangshan University, Ji'an 343000, Jiangxi, China. ${ }^{2}$ School of Life Science, Fudan University, Shanghai 200032, China. ${ }^{3}$ Xijing Hospital of Digestive Diseases, Fourth Military Medical University, Xi'an 710000, Shaanxi, China. ${ }^{4}$ State Key Laboratory of Cancer Biology, Xijing Hospital of Digestive Diseases, Fourth Military Medical University, No. 127, West Changle Road, Xincheng District, Xian, Xi'an 710032, Shaanxi, China. ${ }^{5}$ Department of Oncology, Affiliated Hospital of Shaanxi University of Chinese Medicine, Xianyang 712000, People's Republic of China.}

Received: 8 January 2018 Accepted: 30 May 2018 Published online: 08 June 2018

\section{References}

1. Fuchs CS, Niedzwiecki D, Mamon HJ, Tepper JE, Ye X, Swanson RS, Enzinger PC, Haller DG, Dragovich T, Alberts SR, et al. Adjuvant Chemoradiotherapy With Epirubicin, Cisplatin, and Fluorouracil Compared With Adjuvant Chemoradiotherapy With Fluorouracil and Leucovorin After Curative 
Resection of Gastric Cancer: Results From CALGB 80101 (Alliance). J Clin Oncol Off J Am Soc Clin Oncol. 2017;35(32):JCO2017742130.

2. Van Cutsem E, Sagaert X, Topal B, Haustermans K, Prenen H. Gastric cancer. Lancet (London, England). 2016;388(10060):2654-64.

3. Torre LA, Siegel RL, Ward EM, Jemal A. Global Cancer incidence and mortality rates and trends-an update. Cancer Epidemiol Biomarkers Prev. 2016;25(1):16-27.

4. Ajani JA, Lee J, Sano T, Janjigian YY, Fan D, Song S. Gastric adenocarcinoma. Nat Rev Dis Prim. 2017;3:17036.

5. Tan IB, Ivanova T, Lim KH, Ong CW, Deng N, Lee J, Tan SH, Wu J, Lee MH, Ooi $\mathrm{CH}$, et al. Intrinsic subtypes of gastric cancer, based on gene expression pattern, predict survival and respond differently to chemotherapy. Gastroenterology. 2011;141(2):476-85. 485 e471-411

6. Wang K, Kan J, Yuen ST, Shi ST, Chu KM, Law S, Chan TL, Kan Z, Chan AS, Tsui WY, et al. Exome sequencing identifies frequent mutation of ARID1A in molecular subtypes of gastric cancer. Nat Genet. 2011;43(12):1219-23.

7. Lei Z, Tan IB, Das K, Deng N, Zouridis H, Pattison S, Chua C, Feng Z, Guan $\mathrm{YK}$, Ooi CH, et al. Identification of molecular subtypes of gastric cancer with different responses to PI3-kinase inhibitors and 5-fluorouracil. Gastroenterology. 2013;145(3):554-65.

8. Hanahan D, Weinberg RA. Hallmarks of cancer: the next generation. Cell. 2011;144(5):646-74.

9. The Cancer Genome Atlas Research Network. Comprehensive molecular characterization of gastric adenocarcinoma. Nature. 2014;513 (7517):202-9.

10. Park JH, van Wyk H, Roxburgh CSD, Horgan PG, Edwards J, McMillan DC. Tumour invasiveness, the local and systemic environment and the basis of staging systems in colorectal cancer. Br J Cancer. 2017;116(11):1444-50.

11. Ge H, He X, Guo L, Yang X. Clinicopathological significance of HSP27 in gastric cancer: a meta-analysis. OncoTargets and therapy. 2017;10:4543-51.

12. Cerami E, Gao J, Dogrusoz U, Gross BE, Sumer SO, Aksoy BA, Jacobsen A, Byrne CJ, Heuer ML, Larsson E, et al. The cBio cancer genomics portal: an open platform for exploring multidimensional cancer genomics data. Cancer discovery. 2012;2(5):401-4

13. Gao J, Aksoy BA, Dogrusoz U, Dresdner G, Gross B, Sumer SO, Sun Y, Jacobsen A, Sinha R, Larsson $E$, et al. Integrative analysis of complex cancer genomics and clinical profiles using the cBioPortal. Sci Signal. 2013;6(269):pl1.

14. Wang $Y$, Wang $Y$, Duan $X$, Wang $Y$, Zhang Z. Interleukin-1 receptorassociated kinase 1 correlates with metastasis and invasion in endometrial carcinoma. J Cell Biochem. 2017;119(3):2545-55.

15. de Hoon MJ, Imoto S, Nolan J, Miyano S. Open source clustering software. Bioinformatics (Oxford, England). 2004;20 (9):1453-4.

16. Saldanha AJ. Java Treeview-extensible visualization of microarray data. Bioinformatics (Oxford, England). 2004;20(17):3246-8.

17. Otto T, Sicinski P. Cell cycle proteins as promising targets in cancer therapy. Nat Rev Cancer. 2017;17(2):93-115.

18. Oh JS, Susor A, Conti M. Protein tyrosine kinase Wee1B is essential for metaphase II exit in mouse oocytes. Science (New York, NY). 2011; 332(6028):462-5.

19. Etemadmoghadam D, Au-Yeung G, Wall M, Mitchell C, Kansara M, Loehrer E, Batzios C, George J, Ftouni S, Weir BA, et al. Resistance to CDK2 inhibitors is associated with selection of polyploid cells in CCNE1-amplified ovarian cancer. Clin Can Res. 2013;19(21):5960-71.

20. Mukherjee M, Ge G, Zhang N, Edwards DG, Sumazin P, Sharan SK, Rao PH, Medina D, Pati D. MMTV-Espl1 transgenic mice develop aneuploid, estrogen receptor alpha (ERalpha)-positive mammary adenocarcinomas. Oncogene. 2014;33(48):5511-22.

21. Kumar R. Separase: function beyond cohesion cleavage and an emerging oncogene. J Cell Biochem. 2017;118(6):1283-99.

22. Giaginis C, Giagini A, Tsourouflis G, Gatzidou E, Agapitos E, Kouraklis G, Theocharis S. MCM-2 and MCM-5 expression in gastric adenocarcinoma: clinical significance and comparison with Ki-67 proliferative marker. Dig Dis Sci. 2011;56(3):777-85.

23. Yang C, Wen Y, Li H, Zhang D, Zhang N, Shi X, Jiang B, Ma X, Yang P, Tang $\mathrm{H}$, et al. Overexpression of minichromosome maintenance 2 predicts poor prognosis in patients with gastric cancer. Oncol Rep. 2012;27(1):135-42.

24. Zhao BW, Chen S, Li YF, Xiang J, Zhou ZW, Peng JS, Chen YB. Low expression of $\mathrm{CDK} 10$ correlates with adverse prognosis in gastric carcinoma. J Cancer. 2017;8(15):2907-14.

25. Baba K, Kitajima Y, Miyake S, Nakamura J, Wakiyama K, Sato H, Okuyama K, Kitagawa H, Tanaka T, Hiraki M, et al. Hypoxia-induced ANGPTL4 sustains tumour growth and anoikis resistance through different mechanisms in scirrhous gastric cancer cell lines. Sci Rep. 2017;7(1):11127.

26. Melck A, Masoudi H, Griffith OL, Rajput A, Wilkins G, Bugis S, Jones SJ, Wiseman SM. Cell cycle regulators show diagnostic and prognostic utility for differentiated thyroid cancer. Ann Surg Oncol. 2007;14(12):3403-11.

27. Sparta AM, Bressanin D, Chiarini F, Lonetti A, Cappellini A, Evangelisti C, Evangelisti C, Melchionda F, Pession A, Bertaina A, et al. Therapeutic targeting of Polo-like kinase-1 and Aurora kinases in T-cell acute lymphoblastic leukemia. Cell cycle (Georgetown, Tex). 2014;13(14):2237-47.

28. Markant SL, Esparza LA, Sun J, Barton KL, McCoig LM, Grant GA, Crawford JR, Levy ML, Northcott PA, Shih D, et al. Targeting sonic hedgehog-associated medulloblastoma through inhibition of aurora and polo-like kinases. Cancer Res. 2013;73(20):6310-22.

\section{Ready to submit your research? Choose BMC and benefit from:}

- fast, convenient online submission

- thorough peer review by experienced researchers in your field

- rapid publication on acceptance

- support for research data, including large and complex data types

- gold Open Access which fosters wider collaboration and increased citations

- maximum visibility for your research: over $100 \mathrm{M}$ website views per year

At BMC, research is always in progress.

Learn more biomedcentral.com/submissions 